\title{
Problems and Approaches Analysis of Henan Cultural Communication and Rural Cultural Governance
}

\author{
Man $\mathrm{Xia}^{1, \mathrm{a}}$ \\ ${ }^{1}$ Nanyang Medical College, Nanyang, Henan, China, 473000 \\ aemail,
}

Keywords: Rural Cultural Construction, Cultural Communication, Cultural Governance, Cultural Identity

\begin{abstract}
Rural Communication is concerned that rural communities share the culture and cultural identity of meaning, it can not be understood from the context of the historical context and the realities of rural governance. Country, countryside and farmers is considered elite three main actors involved in the spread of rural culture. Overall, the rural culture of governance under the Pressure System failed to effectively mobilize the spread of the agent (rural cadres) initiative rural culture, but also neglected the participation of farmers. At the same time, networks, process and context of fracture propagation in the presence of rural culture, making it difficult to effectively build the foundation of public cultural action inside the village. In addition to government-led cultural transmission, rural culture in a mixed state. Rural Cultural Construction should be based on the participation of farmers and recognition as a path to promote the rural culture of governance through the "spread consciousness."
\end{abstract}

\section{The Understanding of Cultural Construction in Rural Areas: the Communication Path}

"Problem" in recent years, China's rural culture frequently seen not only the mass media coverage, but also caused the government, academic attention, more and more research and policy papers, especially political science, sociology, anthropology and other disciplines the literature, the mainstream view is that the rural cultural construction is seriously lagging behind in economic and social development, rural public cultural life is diminishing, and decline. It showed a serious lack of public cultural resources in rural areas, to reduce rural public cultural activities and public cultural organizations vacancy. However, an increase in the national rural cultural resources, and the establishment of cultural activities under the cultural background of the organization, field research culture still found in rural areas has not changed much. Perhaps the problem lies not in the rural culture of this "product", but may lie in the intermediary channels and social space. The understanding of contemporary cultural construction in rural China, is inseparable from the analysis of the interaction between farmers and the government, farmers and between farmers and the rural village spread around the culture and generated. Construction of rural culture and communication, for the country, aims to spread the socialist core values, building a harmonious society in rural areas; if the country was undoubtedly based on the position of village cadres, consider public governance and service capabilities in a rural grassroots agents; and from the perspective of the villagers, the villagers are involved in culture and ability to act village identity. This article intends to rural culture as a cultural enrichment activities, not only emphasizes the dissemination of culture-oriented, but also that cultural transmission as an important issue of rural governance. Rural culture is not just the spread of this article of interest, but also involves the impact on rural governance in rural cultural transmission. Specifically, what country, village cadres and farmers in rural cultural transmission of interactive mode? This process produces what results? How rural culture spread? Communication How to promote rural governance? This article is going to answer the question. In this paper, the construction of rural culture in Nanyang City, Henan Province, for the analysis of the case. In which the entire area in Nanyang City in Henan Province

Body point of view, it is in the south of Henan Province. In the process of social transformation, the rural south of Henan province was in line with rural patterns transition general sense. 
Historically, the current practices and future plans panoramic rural cultural construction of Nanyang City to measure the current cultural construction in rural areas, may be able to get a glimpse. 7, 2014 to October, 2015, 6 to 11 months, several research group in four of the town of Nanyang City, and under about 10 villages were home depth interviews with objects including township cadres, village group cadres, villagers and other residents of the town. Meanwhile, the survey also data collection methods herein. The survey was conducted in January 2016 questionnaires were distributed and 250 rural towns in the above recovered 220 valid questionnaires. The proportion of male and female respondents was 43.2: 56.8, educational level distribution of primary school education accounted for 33.2\%, junior high school education accounted for $40.0 \%$, high school education accounted for $14.1 \%$, college level and above accounted for $12.7 \%$ of its occupation involves self , workers, doctors or teachers and other professionals, students, farming (agriculture, forestry, animal husbandry and fishery), unemployed or unemployed, retired, of which the self-employed (20.5\%), workers (29.1\%) and agriculture (20.9\%) mainly . Overall, the sample line with the current situation in rural areas, with a certain representation.

\section{The Actors of Rural Culture Governance: National, Village Cadres and Farmers}

National Policy of Rural Culture and Mass Media Communication. After 1949, in building a new socialist society under the macro background, rural culture into national planning, reconstruction and remodeling among the rural culture can and must be treated as occupied "positions", to serve the country's political objectives (Wu Miao, 2007). In this period, the spread of rural culture are embedded into the structure of the layers spread among grassroots organizations. After the reform and opening up, under the "Development is the last word," the policy guidelines, the construction of rural culture has been to subordinate economic construction, rural cultural development issues are systematically obscured. At one o'clock this period, the construction of rural culture began to be reduced to a cultural and entertainment products, government efforts to promote the cultural construction of almost all concentrated in rural areas, such as providing cultural facilities and cultural products radio, film, television, books and the like on the cultural programs (Wu Miao, 2007), the typical person such as "every village" project. Nanyang City in the rural areas, with the exit of cable radio, television, the Internet has become the main channel for farmers' cultural consumption. Which in turn must pay attention to the deep impact of television on the rural cultural ecology. On the one hand, farmers can enrich their cultural life through television; on the other hand, the nature of the family television viewing makes farmers increasingly away from public cultural life - especially when such a culture is not a pleasant public masses. So, to television as the representative of the role of mass media in the rural culture of the media is two-fold from the opposite point of view, it makes more and more farmers cultural consumption tends to personal.

At the national policy discourse, promoting rural cultural construction "must have position, there is the team with the mechanism." Specific to the practice of local and rural advocacy director of the publicity department as a media regulatory authorities, almost immediately following the requirements of the Central Propaganda Department of the situation issued, less developed or proposed new communications policies, programs themselves. After the newspapers, television stations and other departments restructuring, although by the propaganda department of supervision, but also operate independently, publicity departments should pay attention to just ask for the "three rural" cultural transmission, increase the "three rural" services, but the specific topics set reported by the media to arrange their own hands. Executive-led government or political control of cultural enrichment activities, in some special period can be quickly and efficiently mobilize the entire rural society, but often can not achieve normal development. This top-down "free culture" only temporarily alleviate the emptiness of social living conditions of the rural spirit of it, and by the "savior" attitude makes endogenous rural culture repressed and obscured. As a result, countries vigorously promote the cultural construction in rural dominant, often can not take root, root. Once the state forces retreated from rural society, it advocates cultural style will be difficult to sustain, various public cultural organizations, cultural facilities are unsustainable. At the same time, it used to be called the national discourse defined as ignorant and backward, feudal superstition gradually 
revive cultural activities in rural areas. And this state of chaos also brings a danger to rural cultural anomie. The survey found that maintenance problems caused by the elderly ethical disputes in rural $\mathrm{J}$ City has become one of the main "trivia" village daily coordination process. In some villages, along with the development and lead to increased mobility of the population, some unhealthy performances is staged openly in public, showing a sense of vulgarization trend. More generally, rural spread of Christianity in the rapid proliferation stage. This may be one reason why in recent years, countries once again actively involved in large-scale construction of rural culture. However, the cultural construction in rural areas as a policy, its implementation without departing from the "path dependence" pressurized system.

Rural Culture Propagation under the Pressure System. Nanyang City in the rural areas, the local government to promote the "building integrated cultural village room" (including the "Farm House", sports room, family planning service stations, etc.), "send books, send the film to send literature" and "free culture" countryside activities specific to rural areas or the number of small, cold or the masses repercussions or reduced form. The reason why the village cadres to increase public cultural service entry in the annual work plan, mostly because of higher levels of government performance evaluation requirements, rather than based on a survey of local farmers. Performance evaluation tasks and targets completion, the higher levels of government assessment, evaluation and measurement of lower levels of government "achievements" of the main criteria, assessment results directly related to the vital interests of the examination object. From this point of view, the cultural construction of rural grassroots cadres to the "enthusiastic" but is floating on the surface, inside it actually is not optimistic about this "herd" some history repeat action. In this regard, there are two possible explanations. First, the construction of rural culture with respect to economic development and fiscal revenue functions, it is difficult to obtain "visible" achievements, is often considered irrelevant, which is a kind of "selective treatment." Second, due to the higher levels of government recurrent inspection and assessment, village cadres capable of taking the initiative and little room, village leg to stand on in a variety of "Towards inspection" activities, will not be able to make a real sink to the cultural construction of rural social context go. These are the current cultural construction in rural areas drawbacks.

\section{The Fracture Propagation: Key of Impacting Rural Cultural Governance}

Fracture of Communication Networks: Weakening of Relations and Reconstruction. In rural cultural transmission, direct contact with the object peasant village cadres, but most farmers and village leaders do not care about doing things - that does not infringe their own interests. According to the survey group, for the "village cadres usually focus on whether the case", the respondents chose "no concern" the ratio of $24.9 \%$, "not concerned" and accounted for $34.4 \%$, "indifferent" and accounted for $20.8 \%$, and $80.1 \%$ of the three. In an interview with the village cadres often heard to say: "Now people come to us and we have trouble with their eyes, central government officials are good, we are wicked." The villagers said: "Now the families of each species to go out to work but also by relatives and friends, who find nothing to village cadres ah? village basically no effect, we do not know them, our lives have no influence. "these mixed with a certain degree of negative emotions, including speech all reflect the current situation weaken the relationship between cadres in rural areas. The relationship between cadres weakened, making it difficult to achieve both healthy social interaction. According to the survey, he believes that "the current relationship between cadres and neither cold nor hot," the proportion of $80.5 \%$. Towns and villages merged in recent years, especially aggravated village public culture of collective action based on digestion. This weak communication networks between farmers and village leaders formed undoubtedly affected the relationship between the two. Liteyuehan (2009) that the relationship between people is dynamic, is able to spread through the formation, maintenance and change. The basic unit of relationship is not one person, not two people, but interactive. Village cadres and the interaction model between farmers Reconstruction also failed to adapt to the new needs of the rural cultural transmission.

Fracture of the Communication Process: Derailment of Content and Demand. Rural 
Cultural Construction of masking the wishes of farmers and subjectivity, and cultural resources of farmers close relative increase in autonomy, is the leading cause of fracture propagation process. With the improvement of living standards of farmers, their cultural consumption structure, consumer attitudes are undergoing profound changes, the rapidly growing need for cultural life, only a one-way delivery of movies, theater or theatrical performances can not meet the needs of farmers . Thus, a paradox emerged. On the one hand, rural cultural life is monotonous and boring slack work when playing mahjong when busy, playing cards, or a true portrayal of many farmers in cultural life; on the other hand, farmers in the village cultural facilities usage, cultural organizations, cultural activities the participation rate is relatively low, more and more farmers in cultural activities tend to personal, small groups of. However, initiated by farmers themselves, organize cultural events wishes and preferences are still high emotional foundation. According to the survey "Do you want some more villagers in the village self-organized cultural events?" One of the statistics, select the "highly desirable" and "would prefer" were up $46.8 \%$ and $33.6 \%$. Since it is a process of cultural transmission of dynamic development, it can not be done overnight thought I could solve the problem of rural culture. The field of vision at work in many rural cadres, higher levels of government to complete the task of building cultural arrangement would mean an end to such actions, it is inevitable does not impair the effect of the spread of rural culture.

Fracture of Propagation Context: Lack of Village Memory and Community Sense. First, as a social interaction affects the memory of the village peasant village cadres of behavior accepted and recognized. Due to historical reasons and the relative neglect of farmers' participation, cultural significance for the construction of rural village cadres and villagers are very different, which led to a "communication helpless." On the one hand, rural-based interactive post facto, most of the villagers have formed a cadre behavior stereotype, and even questioned whether they are to gain some personal interests.

Second, the lack of a sense of community and village experiences of collective cultural expression action encountered difficulties. Faults and lack of young migrant population caused massive rural cultural talents, the villagers "atomization" of television and popular culture on the village public action based on digestion, interpersonal interests of the villagers, destroy all the common experiences to create a village. Village cadres reality-based judgment that "cultural activities in rural areas is now a lack of people, did not make up", although villagers expect a richer cultural life, but gradually formed a collective "impossible" consciousness: "Now the village is not only young, is the fifties and sixties, as long as the body good people also go out to work, how to engage in leisure and cultural activities ah? young people attend school, work work, doing housework occasionally idle morning, afternoon playing mahjong, night Watch TV, like this. "No doubt, influenced the spread of breaking a common understanding, and a lack of effective community experience, but also that farmers receive and the positive response to the initiative of public cultural construction in rural areas difficult to produce.

\section{The Mix of Rural Cultural Identity: Tradition Decline and Innovation Diffusion}

Traditional Native Chinese since 1949 after several political campaigns, to non-collectivization, recent tax reform, new rural construction, substantially advance along the path of urbanization in the country's modern discourse. A purely local China has ceased to exist. Rural cultural mix of traditional culture (Folkways), modern culture (Science and Civilization) and popular culture (mass media and urban). It is an emerging cultural hybrid state. As a traditional temple culture has become increasingly common decline in Nanyang City most towns, but in the economy is relatively backward WJ town still got Survival. In the town of H HY Um village, has a fixed annual temple festivals, such as dragon and lion dances, cross-stitch Tam and other local folk performances, as well as Yang troupe singing add to the fun, for the village and nearby villagers, is indeed a great events not only provide an opportunity for the sale of goods for farmers, they also become the place to relive memories. It is said that as long as the temple, the young migrant workers back to the village on time will also participate in various performances. Examples of the region, "the only remaining" traditional folk temple fair attractive to farmers seem far better than "free culture" 
activities in the countryside, especially for the elderly. $\mathrm{H}$ temple president said that since 1991 they secretly do temple, has worked with township and village cadres and calendar after the conflict, "repeated the struggle." $\mathrm{H}$ think they do in the temple is "serving the people": "Older people usually no entertainment, when it held the temple to help, all in high spirits." For the elderly, in addition to entertainment temple, it is a life experience in their social networks.

Overall, although the impact of the traditional elements of rural culture increasingly weakened, urban culture and mass media dissemination of culture continue to penetrate into the local society, showing a mixed situation, but the traditional strength still can not be ignored, and cultural patterns of newborn still in formation, and shows the potential to be widely disseminated, this may be a positive side of the cultural ecology of rural portrayal.

\section{Rural Cultural Awareness and Communication Integration Communities: Generation Conclusion}

In summary can be found in rural culture spread one-dimensional, because too much emphasis on conveying information and culture as the goal to transform the rural, often overlooked cultural transmission agent activity, but also ignored the farmers' cultural identity and active participation. Farmer aphasia in the cultural construction in rural areas will not be conducive to the sustainable development of rural culture, is not conducive to social harmony and stability in rural areas. That emphasizes two-way interaction, engagement, identity-oriented rural culture propagation thinking needs to be stressed that in order to use it to repair the relationship between the spread of this break. In this group of urban culture places as the control that the rural culture also requires a cultural consciousness, and this consciousness needed to achieve by means of propagation. And other studies related to the construction of rural cultural differences, the group did not try to the next "rural culture" a precise definition. Instead, the research group believes that culture is in a rural reconstruction, plastic, the formation of a social process. The key is not the rural culture "what", but it became the "what is" the way, the path. This is not an overnight process, but sustained Symbolic Interaction, in consultation with the adjustment process. In other words, look at rural and cultural needs of a dynamic contact angle.

From the perspective of Cultural Communication Studies in rural areas, the focus of their academic and social care is to spread and rural cultural identity relationship. Construction of cultural identity was the basis of social integrity, but "due to the excessive emphasis on unilateral transformation of rural culture, cultural identity crisis thus continue to emanate. Imagination and the definition of the identity of extreme opposites and yet make the difference on the bottom of this identity had doubts and mistrust "(Zhao Xudong, 2007). Today, the spirit of rural culture of governance, should be to rebuild confidence of rural culture and identity, which requires the integration of rural communities through interpersonal communication and mass media based on the relationship between the audience and communicators. On the definition of mass media audience crowd it is difficult to achieve clear and concrete, interpersonal communication is still the most effective governance of rural culture and key areas for improvement. Frye Rand had proposed to "spread the integration of the community" as the path to all levels of the community to disseminate, integrate media axis. Different communication and media define different communities. In one community, the process of shaping the identity of the operating process is actually spread, on this basis, to expand the national political identity nation. This is the so-called Cultural Construction of political identity, or rural governance through cultural transmission. Rural governance through cultural transmission, emphasizing the thinking of rural governance should experience "cultural turn" should at least be a "cultural renewal" to the idea of reforming the social order in rural areas. From the micro and begin with the grassroots political power, village-level organizations in promoting government-led cultural need to adjust the mode of propagation, and enhance everyday rural cultural construction, and strive to obtain acceptance of the initiative and active participation of farmers. From a macro point of departure, it should be the gradual elimination of the negative impact of rural governance in the pressurized system, and promote government-led culture and local culture symbiotic culture of farmers in rural culture really agree with, but also committed to 
eradicating rural backwardness and ignorance of cultural bias .

Harrison (2002) has pointed out that the causal relationship between culture and progress are complex, but the power of culture is visible. Of course, to be precise, here it refers to the strength of cultural transmission. It is not one-dimensional pressure type cultural mobilization, but participatory communication, is based on the construction of rural cultural identity awareness, for rural culture, "dissemination of consciousness": Let those left behind to enjoy the local music, so that the flow of young Local generation capable of caring, a real "cultural feedback"; the farmers concerned or the relevant body Countryside Jieneng participate in shaping and dissemination of rural culture to achieve sustainable development of rural culture.

references

\section{Acknowledgements}

Fund Project: 2016 Annual Henan Science and Technology Agency Soft Science and Technology Projects (162400410612);

\section{References}

[1] Fei Xiaotong. Local Chinese and Local Reconstruction. FY Times Publishing Company, 1993

[2] Fei Xiaotong. Peking University, Vol. 3 (1997) No 27, p.74-76

[3] Hou Bo, Tan Ying. China Agricultural University, Vol. 3 (2006) No 19, p.144-145

[4] He Xuefeng. New Rural China: Transformation of Rural Society Survey Notes. Guangxi Normal University Press .2003

[5] He Xuefeng. Economic and Social Systems, Vol. 3 (2005) No 27, p.57-60

[6] Liang Shuming. Theory of Rural Construction, Shanghai People's Publishing House, 2006.

[7] Lin Fuyue. Chengchi University Department of Journalism Doctoral Dissertation, Vol. 4 (2002) No 27, p. 52-54 